\title{
Analysis on the Space Commonality of Chinese Calligraphy and Painting
}

\author{
Kun Li \\ School of Art and Design \\ Huanghe Science and Technology College \\ Zhengzhou, China \\ e-mail: 27188207@qq.com
}

\begin{abstract}
Inscription plays a unique and irreplaceable role in composition, which is a necessary part while expressing mood in Chinese painting. The reason for inscription playing a unique role in being able to coexist harmoniously with the painting and image in Chinese painting, is mainly due to the space commonality of Chinese calligraphy and painting.
\end{abstract}

Keywords-calligraphy; space; inscription; integration

\section{INTRODUCTION}

Inscription is an important part of Chinese painting composition, which plays an important role to improve the picture composing. On this point, there are two questions need to be answered:

First, inscription as part of the composing pictures, can it be replaced by other images which will also be perfect to achieve the purpose of composing pictures? For example, replace the inscription in landscape by mountains, trees etc, and replace the inscription of flowers and birds pictures by flower, leaves, stones, etc., will the effect on composing pictures be the same with the former inscription?

Second, the space in traditional Chinese painting is different from the realistic three-dimensional space in traditional western painting; it is a kind of space built on the basis of multi-view perspective. The space in calligraphy has been considered as two-dimension (which is plane, with no third dimension depth), then will it be harmonious to create deep space images? How to achieve this spatial integration?

Here it is necessary to analyze the interlinked relationship of the spatial characteristics in calligraphy and Chinese painting because of the inscription (the special screen image) of calligraphy.

\section{THE SPATIAL CHARACTERISTICS OF CALLIGRAPHY}

Zong Baihua considers that Chinese painting and calligraphy all come through dancing: "extending from the dance moves, showing out of virtual space, which constitutes a special style of Chinese painting, calligraphy, and theater as well as architecture." So how does this special character of dancing be reflected in the space of calligraphy and painting? Chinese calligraphy is the art of lines, building characters even the whole chapter with lines. While appreciating a calligraphy, viewers can experience the characteristic of time (i.e., the chronological process of writing is unrepeatable, like music), but can they experience something of the space? Arnheim describes it as this: "draw a straight line on a paper; it looks like the line is not located within the paper but suspended above it ... Obviously, this phenomenon is not caused by the physical object itself, but from the psychological reactions of the observer. So how does this kind of psychological experience be generated? We can see that if this line is truly located within the paper that the paper will inevitably fall into divisions; if it looks like a straight line located in the space above the paper, the paper will remain in continuous complete with original status. In addition to these two possibilities, the third case may also occur ...it seems to be pictures cut into pieces of paper with scissors; through these pieces of pictures, we see the dark space below the white paper. In this case, the space where the white paper lies also fell into divisions."

Three experience cases are described here: the first one is that the line is at surface of the paper, the line is at the same plane with the paper surface, but the lines divided the paper surface into two parts; the second one is that the line is floating above the plane of the paper; the third one is that the line is below the paper and the paper became chart, the line is at the bottom. In the second case (lines, namely calligraphy image "floating" in the space above the paper), in this space, along with mood, the rhythm of the lines changes, then transfers into ever-changing patterns - lines "move" up. By dynamic movement, it produces a rich aesthetic experience; this sense of movement is "dancing." Experience shows that this sense of movement is an illusion, the illusion disappears while leaned viewing, "a painting can not be moved", and it turns into a stationary.

This is a relationship between "picture-bottom". "Picture" is the calligraphy image of Chinese characters, which is separated from its background - the paper (paper occupies a large area and has continuity which is called "bottom"), this separation is not a separation on physical sense, but our attention is attracted by the character, whether it is white on black or black on white. Background is not meaningless, it constitutes an important role in calligraphy space for the spreading of lines provides a broad space; and brings us a rich aesthetic experience. Otherwise, lines are only dead 
outlines, we can not feel the "一" (heng) array as thousands of miles of cloud which is faintly visible in fact, 'Dian' (dot) as falling stone from peak or a kind of collapse of the real stone"( Mrs Wei 's "Bizhentu - A works on writing strokes ").

Inquiring and appreciation of skills and rhythm of pen using are also proceeding in this case. "Each stroke in its form" refers to potential, strength, rhythm of things movement, does not refer to the image of specific things. Calligraphy shows moods and emotions of things, and manifests the movement of objective facts. Through the rhythm changing, line can simulate modal of things, in which way, lines have the vitality out of the paper and the illusion of movement. There is no reference in reality for this illusion, however, we are able to truly feel it.

Such as "The Volume for Mu Yuan in Zhenjing Temple" written by Yang Weizhen in the Yuan Dynasty, looking in the distance, we can see the font size is strongly changed and the thick and pale ink color fluctuate, adding to each other's splendor. The space of the whole piece of calligraphy is divided by line. The characters of thick color seem to struggle to free themselves from the paper and fly to the outside of the paper. The characters in pale color written by dry brush are relatively dim. Two of them just like an array of stars in summer night and the light and shade alternate. Coming up to observe it, we can feel that the spatial illusion disappears and just see the tracks of using a brush. For another example, "The Cursive Script of Poetry Volume of Tang People" written by Wang Duo in Ming Dynasty, the line spacing changes ups and downs. Putting the characters in thick color and characters in pale color together forms sharp contrast, and the sense of space tends to fluctuate. So grand spatial distribution of white with ups and downs and smooth and rhythmic line rendering embody the aesthetic ideal "like flying and like moving".

Therefore, the change of word size and thickness of line as well as rhythm of pen and other factors will affect the spatial experience of calligraphy. While appreciating calligraphy, those words with thick ink and big shape, always leap into our eyes first, then those light ink and small words, which results an "ups and downs" illusion in space. So, instead of saying that characters are "floating" in the space above the paper, they situate in the space created by themselves.

However, not all calligraphy has the sense of ups and downs. In some works with relatively uniform stroke and ink shades, and with small changes in the magnitude of the work, similar line with average space regularly repeated with small fluctuations, all these presented a flat feel to the audience. For example, compared with the "The Volume for Mu Yuan in Zhenjing Temple", the work of Huizong in Song dynasty presented a flat characteristic with thin gold equalization font size, little changes in line thickness, average pen rhythm and neat array. Another example is in the work of Xia Yong (Yuan Dynasty): "Painting of Tengwang Pavilion" and "Painting of Fengle Building", the line of its inscription is arranged with dense distance, and the marginal white is uniform, presenting a significantly planar feature.
The line in Chinese calligraphy, in terms of font, the seal script, official script and regular script tend to be static with implicit dynamic, spatial distribution within the word is regularly, and thus tends to planarity; while running script and cursive script with thick and thin , shade, wet and dry, change of font size, as well as the change of pen speed, raising and pressing as well as turning rhythm, and uneven spatial distribution within the word, and weak laws, often appearing with "unexpected" marginal white, and to the visual form, all of which gives a rich aesthetic experience in the form of vision, and tends to present dynamic spatial characteristics.

\section{SPATIAL CHARACTERISTICS IN CHINESE PAINTING}

The space in Chinese painting and Western traditional painting is different; tradition Western painting uses perspective method to mimic nature in order to reach plausible illusion, pictures have been painted over, leaving no gaps. Space created in Chinese painting does not use this perspective method, pictures will not be filled with all the space; the space type in Chinese painting is built on more than one point of view, which is located in the high mountains overlooking the distant universe, it is an understanding of nature, rather than mimic the threedimensional illusion (the space of near, medium, and far in Chinese landscape painting is turning back regularly).

In fact, Chinese painting is affected by calligraphy; the building of space sense is closely linked with calligraphy. $\mathrm{Mr}$. Zong Baihua believes that the space consciousness in Chinese painting is based on the space performance power of Chinese calligraphy art. He said: " space structure of Chinese painting is neither foiling of shadow (Chinese ink painting is not real writing of light and shadow, but an abstract ink performance), nor the geometric perspective of moving statue's construction, instead, it displays a similar sense of space caused by music or dance. Exactly speaking, it is a kind of space creating in calligraphy. Chinese calligraphy is a similar rhythm art form of music or dance. It has the beauty of lines, and emotional and personality performance. It is not to describe the physical things, but not completely abstract as the Western alphabet; it maintains the implying posture of physical and life. "The space in Chinese painting is not completely portraying of physical things, but describing the chest out-gassing by the author's mind wandering, and " an allosteric odd spirit in outside world." The space in Chinese painting is to wander with spirit, and make silk paper turned into infinite universe, which is bulging with vibrant flavor of the universe. The image of the painting is being suspended in space; and when black or white is assigned of the universe gas, thus makes movement and interaction namely "vivid." Vivid and blank are interrelated with each other, if the space is divided unreasonable, which will affect the flow of the breath, thus affecting the aesthetic appreciation of the subject. Blank silk paper becomes a far boundless space, which makes mind wander in it and forget to leave.

This illusion of space is one of the performance characteristics of Chinese painting. Therefore, the threedimensional space in Chinese painting is different from the real space in traditional Western painting, but creating a 
space where people can fugue, which is common in music and dance and even calligraphy. Because of its distance from the real reality, therefore it can stimulate people's imagination effectively, so as to achieve the purpose of lingering, hanging around and readiness to stay.

"In theory of 'Strange', as painting is not equal to landscape; in the theory of exquisite of pen and ink, landscape is not as good as pictures." (Dong Qichang's "Essay on Meditation Hall for Painting") Chinese painting is not to mimic nature but to construct a new mood of ink for the objective, constructing a spiritual world different from the reality using calligraphy pen and space. This is the same as traditional Chinese opera, with few sets on stage, and the beauties of springtime, pavilions and buildings as well as the millions of soldiers are relying on the actors' performance on the stage, which can be revealed in the heart of audience; the unrealistic stage set did not influence people's appreciation. In Chinese painting, all of which are caused by a special component - blank, so the composition is called "marginal white" in Chinese painting and calligraphy theory.

\section{INTEGRATION OF CALLIGRAPHY INSCRIPTION AND CHINESE PAINTING SPACE}

Chinese painting takes blank screen after the completion as a factor to create space to run and use, which is completely different from the Western painting by plastering the entire picture. Blank in Chinese painting is meaningful as blank in calligraphy, and can intrigue mood about the picture mostly. "Virtual or real, blank part can be a place of Wonderland." (Da Chongguang's "Tricks of Painting") Blank is the stage to stimulate the imagination, provides the required space for souls to dance.

The process of writing or painting is the spatial segmentation process, the blank is the result of this process, and this gap is not meaningless or passive, it is a gathering of cosmic gas, and it provides endless space for the "fugue" of aesthetic subject. "For blank, it is beneficial with it, and useful without it." (Laozi's "Tao Te Ching") With the completion of the writing or painting, the divided space gradually shows the relationship between each other. Prior to the completion of the work, a blank paper or silk is still a space in the absence of external driving and under no influence of trend with no purpose, but once the work is complete, the division of space clear up, under the drive of the online and offline combination, showing orderly, lively, and vitality movement. Air of the universe flows in space, it squeezes each other and ultimately find a balance, so this space has a reaction to the image, it also drive the space of combination of lines.

It is this commonality of space in Chinese calligraphy and painting, manufactures conditions for inscription which plays a unique role in fusion and harmony of Chinese painting. Books and paintings together constitute a harmonious gas dance in space background.

As an inscription for pictures, calligraphy is bound to lose some independence and integration into the pictorial space, this kind of ups and downs is bound to coordinate and echo with a space sense of the screen. Because of the characteristics of calligraphy space, it "floats" on the screen with a certain depth. The ending character and its distribution is different from the individual calligraphy; just considering the relationship with the overall space, and associating with three-dimensional space of the whole picture, which will result in different spatial relationships. The space mood in Calligraphy has to be compatible with the space mood of the picture, and go into the screen space. For example, in Zhao Mengfu's work "Painting of Mt. Que and Mt. Huabuzhu in Autumn", grass, trees, houses, mountains promote regularly, inscription is clearly in the middle of ground and background which can make the picture with more abundant levels. Another example is the work of Cao Zhibai (in Yuan dynasty) known as "Painting of Woods in Winter", the screen creates a deep and vague space, trees in front shows reclining posture and stretching as patchwork, inscription at the top right changes obviously in shades, the first line in the right is the most concentrated rough, then gradually fades, undulating, arranging on pronged missing, getting shorter from right to left, as if retreating gradually to the depths of the picture with shades winking, and it echoes with the picture auxiliary assisting to create atmosphere for screen space. If inscription here is replaced for the distant mountains or trees, the existing space and composition would be undermined.

Therefore, the role of the inscription in the composition is unique and irreplaceable, if the inscription in landscape was replaced for mountain, there would be screen congestion caused, so that the screen would not breathe smoothly. Inscription is not an option, but a necessity for space and mood expressing in Chinese painting. The reason for inscription playing a unique role in being able to coexist harmoniously with the painting and image in Chinese painting, is mainly due to the space commonality of Chinese calligraphy and painting.

\section{REFERENCES}

[1] Pan Yungao. Discussion on Calligraphies and Paintings of Han and Wei Dynasties and the Six Dynasties [M]. Changsha: Hunan Fine Arts Publishing House, 1997.

[2] The Complete Book of Chinese Calligraphies and Paintings: Vol. 14 [M]. Shanghai: Shanghai Calligraphy and Painting Publishing House, 1999.

[3] Pan Yungao. Discussion on Paintings in the Song Dynasty [M]. Changsha: Hunan Fine Arts Publishing House, 2000.

[4] Selected Papers of Calligraphies in All Previous Dynasties [M]. Shanghai: Shanghai Calligraphy and Painting Publishing House, 1979.

[5] The Complete Book of Chinese Calligraphies and Paintings: Vol. 8 [M. Shanghai: Shanghai Calligraphy and Painting Publishing House, 1994.

[6] (US) Rudolf Arnheim. Art and Visual Perception [M]. translated by Teng Shouyao, Zhu Jiangyuan.

[7] Zong Baihua. Strolling in Aesthetics [M]. Shanghai: Shanghai People's Publishing House, 1981. 